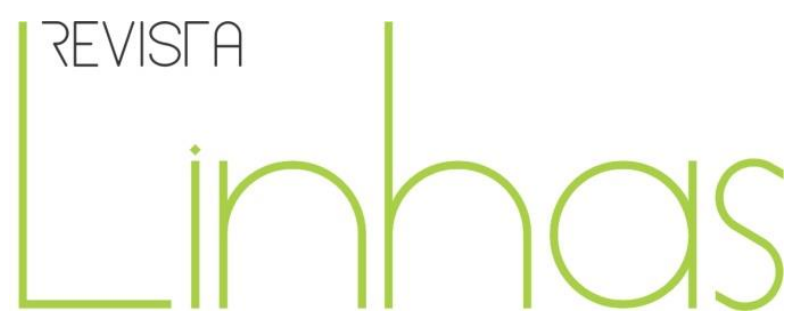

\title{
Chapeuzinho Vermelho e versões simplificadas: cuidado com a roupa do livro, ela pode enganar
}

\section{Resumo}

O presente artigo tem como objetivo analisar uma versão do conto de fadas Chapeuzinho Vermelho, indicado por crianças do $4^{\circ}$ ano do Ensino Fundamental de uma escola pública de Presidente Prudente/SP, como um de seus títulos favoritos. No entanto, não entendemos esta versão como literatura, por se tratar de uma adaptação sem qualidades literárias. Neste sentido, assim como o lobo mau pretere a protagonista com as roupas da avó, muitos livros infantis também enganam, quer pelas ilustrações, quer pelos paratextos. Versões como estas são chamadas de versões simplificadas, estão muito presentes em salas de aula e em bibliotecas escolares e são objetos de escolha para leitura tanto de alunos quanto de professores. Neste artigo, analisamos uma versão simplificada de Chapeuzinho Vermelho em relação aos aspectos verbal, visual e de paratextos, bem como às particularidades do conto de fadas, a fim de destacar as distâncias entre literário e não literário. Esperamos, com essa discussão, alertar professores, bibliotecários, mediadores de leitura, para tal discernimento e para a compreensão de que nem todos os livros destinados às crianças são considerados literatura infantil. Assim, futuras escolhas, quando bem articuladas com a análise dos livros infantis e com os objetivos de leitura, podem contribuir para a formação do leitor literário.

Palavras-chave: Literatura Infantojuvenil. Dialogismo (análise literária). Leitura - Estudo e Ensino.

\section{Para citar este artigo:}

SANTOS, Ana Laura Garro dos; SOUZA, Renata Junqueira de; FEBA, Berta Lúcia Tagliari. Chapeuzinho Vermelho e versões simplificadas: cuidado com a roupa do livro, ela pode enganar. Revista Linhas. Florianópolis, v. 18, n. 37, p. 78-107, maio/ago. 2017.

Ana Laura Garro dos Santos

Universidade Estadual Paulista UNESP - Brasil

analaura.garros@gmail.com

Renata Junqueira de Souza

Universidade Estadual Paulista UNESP - Brasil recellij@gmail.com

\section{Berta Lúcia Tagliari Feba}

Faculdade de Presidente

Prudente - FAPEPE - Brasil berta.tagliari@gmail.com 


\title{
Little Red Riding Hood and simplified versions: beware of the book clothes, it may deceive you
}

\begin{abstract}
The present article aims to analyze a version of the fairy tale Little Red Riding Hood, indicated by $4^{\text {th }}$ grade Elementary School children in a public school in Presidente Prudente / SP, as one of their favorite titles. However, we do not regard this version as literature, because it is an adaptation with poor literary qualities. In this connection, just as the bad wolf tricks the girl into her grandmother's clothes, many storybooks for children also deceive either on account of the illustrations or on account of the paratexts. Versions like these are called "simplified versions", they are frequently present in reading classrooms and school libraries, being a reading choice for both students and teachers. In this article, we analyze a simplified version of the Little Red Riding Hood in relation to verbal and visual aspects, as well as to paratexts, and particularities of the fairy tale itself, in order to highlight the distance between literary and non-literary texts. With this discussion, we expect to alert teachers, librarians and reading mediators to such discernment and to the understanding that not all books intended for children are considered children's literature. Thus, future choices, when well articulated with the analysis of such books and with the reading objectives, may contribute to the development of the literary reader.
\end{abstract}

Keywords: Children's Literature. Dialogism (literary analysis). Reading - Study and Teaching. 


\section{Introdução}

Este artigo faz parte das conclusões e dos resultados obtidos na pesquisa de mestrado ${ }^{1}$ intitulada As várias Chapeuzinhos Vermelhos: contos e recontos a partir das preferências de um $4^{\circ}$ ano do Ensino Fundamental, vinculada ao Programa de Pósgraduação em Educação da Faculdade de Ciências e Tecnologia da Universidade Estadual Paulista "Júlio de Mesquita Filho" (UNESP) e desenvolvida entre os anos de 2014 e 2016 em uma escola pública da cidade de Presidente Prudente/SP. Por entendermos que a leitura é um dos principais meios de se obter informações e conhecimentos, concordamos que ela deva ser trabalhada nas instituições escolares de forma que os alunos não a façam apenas "mecanicamente", mas sim que compreendam o que leem. Neste sentido, percebemos que o que favorece a formação do leitor, no âmbito de sala de aula, é o ensino de Literatura Infantil. No entanto, consideramos que é necessário que alunos e professores tenham a percepção de que o texto literário tem suas singularidades, tais como: o contexto, as experiências do leitor e a situação de provocar, a todo tempo, a imaginação.

Em um dos momentos da pesquisa em questão foi perguntado às crianças, individualmente, qual era o seu conto de fadas favorito. O título que apareceu com mais frequência foi Chapeuzinho Vermelho. Assim, uma das autoras desse artigo, fez um levantamento de todas as versões deste título presentes na escola, alvo da pesquisa e, selecionou: um conto de fadas tradicional, um reconto e uma versão simplificada. Dessa forma, o principal objetivo da pesquisa foi analisar os contos de fadas sugeridos pelas crianças de um $4^{\circ}$ ano e as relações entre paratextos, texto verbal, texto visual e estratégias de leitura, conceitos que serão discutidos no decorrer desse escrito.

Neste artigo, porém, optamos por expor e discutir apenas uma análise da versão simplificada de Chapeuzinho Vermelho. Os motivos para tal escolha foram: primeiramente por não a reconhecermos como literatura, pois se trata de uma versão sem qualidades literárias; depois, porque, apesar disso, estas versões estão muito presentes em salas de aulas, bibliotecas escolares e são objetos de escolhas para a leitura tanto de alunos quanto de professores.

\footnotetext{
${ }^{1}$ Pesquisa financiada pela Coordenação de Aperfeiçoamento de Pessoal de Nível Superior - CAPES.
} 
Para embasar essa discussão, o artigo será organizado da seguinte maneira: teorias e conceitos do conto de fadas tradicional e do reconto; conceitualização sobre o texto verbal e o visual (ilustrações) nos materiais de literatura infantil; definição sobre o papel dos paratextos nos escritos infantis; por fim, analisamos um conto de fadas simplificado indicado pelos alunos da pesquisa; e traçamos as considerações acerca da seleção de livros para crianças e do papel da escola na formação do leitor. Esperamos, com isso, oferecer argumentos tanto para professores, como para bibliotecários a respeito das escolhas dos materiais literários de leitura dos alunos do Ensino Fundamental, anos iniciais.

\section{As particularidades do livro infantil}

Nos livros destinados às crianças, há várias características que chamam a atenção do leitor mirim. Dentre elas está a materialidade, caracterizada como formato, tamanho, textura, cores. No entanto, para ser considerada de boa qualidade, “[...] os formatos, as capas, as guardas, folha de rosto e páginas do miolo devem na maioria das vezes ser vistas como um conjunto coerente" (LINDEN, 2011, p. 51). Em outras palavras, os envolvidos na publicação do livro (autor, ilustrador e editora) precisam planejar o design do produto para, ao final, gerar os efeitos possíveis da polissemia da obra.

No que se refere ao formato, são mais comuns os verticais, os horizontais e os quadrados. O primeiro, segundo Linden (2011), é o mais frequente. Além dos citados acima, há os de contornos irregulares, como os que têm forma de animais. Vale ressaltar que "[...] o formato [...] não é acidental, mas participa da totalidade estética do livro" (NIKOLAJEVA; SCOTT, 2011, p. 307).

Além do formato, o tamanho do livro também é pensado. Sobre isso, Linden (2011) aponta três categorias em função das mãos do leitor: os abertos, que podem ser segurados com apenas uma das mãos, como os de bolsa. Os fechados, que podem ser segurados com apenas uma das mãos, mas que necessitam das duas para serem manuseados e os que podem ser pegos com as duas mãos e devem ser lidos com algum suporte, como a mesa, o colo. Quanto maior o livro e menor a criança, mais a leitura será uma diversão. 
Outro aspecto atrativo aos olhos dos leitores mirins é a textura. Há os livros de banho, que são livros para serem lidos e oferecidos para as crianças no momento em que estão na água. Neste caso, é habitualmente explorado por bebês devido ao fato de o material favorecer o manuseio pelo tato e pela boca, posto que, nessa fase, esse comportamento é bastante comum. Há, também, os livros de pano, comum também entre os bebês, pois não rasgam e podem ser utilizados com criatividade.

Dessa maneira, a materialidade de um livro tem sua função e deve ser arquitetada para atender aos interesses e às expectativas do leitor, afinal a questão estética é algo que atrai para a escolha, o manuseio e a leitura. Contudo, o que é comum encontrar nas escolas são livros com formatos pequenos ou tipos de papéis inferiores apenas para economizar e não com o objetivo de contribuir para a construção de sentidos do texto.

A materialidade, o design e o formato fazem parte de qualquer livro, seja ele infantil, seja ele um livro de poemas, de palavras-chave ou um conto de fadas. Como a obra que será analisada neste artigo é uma versão de Chapeuzinho Vermelho, discutiremos a seguir o gênero conto de fadas.

\section{O gênero Conto de fadas}

Chapeuzinho Vermelho é um livro infantil do gênero conto de fadas. Tal gênero também tem suas particularidades que acabam por estimular o interesse do público infantil até os dias atuais. Bettelheim (1980, p. 153) comenta que os contos de fadas “[...] começam exatamente onde a criança está emocionalmente, mostrando-lhe para onde ir e como fazê-lo.". Ainda mais importante, eles o fazem “[...] na forma de material fantasioso que a criança pode moldar como lhe parecer melhor, e por meio de imagens que tornam mais fácil para ela compreender aquilo que é essencial que compreenda”.

Coelho (2003) entende que esse fascínio ocorre porque quem lê o texto acaba por se encontrar numa atmosfera na qual suas próprias pretensões parecem se suceder, "Daí o prazer interior ou a sensação de auto-realização que os contos de fadas ou os contos maravilhosos transmitem" (COELHO, 2003. p. 114). A autora ainda declara, em seu livro $O$ conto de fadas, que o gosto ocorre porque 
[...] todo esse mundo mágico ou sobrenatural, próprio do arcaico, expressa, no nível do sonho ou do imaginário, as lutas e paixões que o ser humano enfrenta no mundo real, para encontrar aí o seu lugar verdadeiro ou para alcançar sua auto-realização. (COELHO, 1991, p. 79, grifo da autora)

Recuperamos Bonaventure (1992, p. 123), para quem “[...] crescer é viver seu destino, nos dizem os contos, passar por momentos de conflitos externos e internos, perdas e confrontos difíceis; mas no fim acaba-se encontrando o tesouro que enriquece o resto da vida." Neste sentido, quando o leitor tem acesso ao conto, vivencia todas as suas etapas, procurando resolver os conflitos e alegrando-se ao final, quando tudo retoma o equilíbrio.

Diante do exposto, destacamos a importância de despertar o interesse pelos contos de fadas nas crianças, desde a mais tenra idade, uma vez que esse gênero pode contribuir significativamente na formação humana.

No que diz respeito à estrutura, nos contos de fadas devem estar evidentes o começo, o meio e o fim. Quanto ao começo, os contos de fadas

[...] caracterizados por começarem, tanto nos relatos orais, como nos escritos, por Era uma vez - expressão mágica que nos põe à escuta dessas milenares histórias maravilhosas, ocorridas em reinos distantes, florestas escuras, com muitos obstáculos a vencer, caminhos novos a trilhar, identidades a descobrir no encalço do sentido da própria vida -, e terminam com o já conhecido "e viveram felizes para sempre..." Assim, início e fim são indicativos do gênero a que essas histórias pertencem. (RIBEIRO, 2012, p. 215, grifo do autor)

Além disso, o espaço e o tempo da história devem estar claros. Pode-se afirmar que o começo, além de nos sinalizar quanto ao gênero a ser lido/ouvido, resume-se na apresentação dos personagens. Regularmente, “[...] há aqui a apresentação de uma situação tranquila até que algo a perturbe. Geralmente antes da perturbação, o leitor percebe o local onde se passa a história e as personagens que vão vivê-las" (GIROTTO; SOUZA, 2014, p. 31). O tempo deve ser pensado no sentido de tempo verbal, geralmente com expressões de “Era uma vez", "Há muito tempo”, entre outras. 
“O meio são ações ocorridas entre os personagens que compõem causalidade: é neste momento, é nessa parte do enredo, que percebemos uma sequência de eventos que formam a história" (GIROTTO; SOUZA, 2014, p. 31).

“Já o fim, este momento mostra como a ação perturbadora foi resolvida e se as coisas no enredo voltam ou voltarão a ficar da forma como foram apresentadas antes da perturbação" (GIROTTO; SOUZA, 2014, p. 31). Como forma de sintetizar esses três atos, as autoras elaboram o seguinte quadro:

Figura 1: Era uma vez... uma caixa de histórias: prosa no acervo

\begin{tabular}{|l|l|}
\hline \multicolumn{1}{|c|}{ Narrativa - Esquema de 3 atos } & \multicolumn{1}{c|}{ Especialidade do ato } \\
\hline $\mathbf{1}^{\circ}$. ato: Início/Situação inicial/Introdução & $\begin{array}{l}\text { Há uma situação estável até aparecer } \\
\text { algo que a perturbe. }\end{array}$ \\
\hline $\mathbf{2}^{\circ}$. ato: Meio/Complicação/Desenvolvimento & $\begin{array}{l}\text { Apresentação da perturbação e a } \\
\text { necessidade de voltar a uma situação } \\
\text { estável. }\end{array}$ \\
\hline $\mathbf{3}^{\circ}$. ato: Fim/Situação final/Conclusão & $\begin{array}{l}\text { Neutralização da perturbação e volta } \\
\text { à } \\
\text { estabilidade. }\end{array}$ \\
\hline
\end{tabular}

Fonte: GIROTTO; SOUZA, 2014, p. 31.

Silva (2009) também apresenta outras especificidades do gênero conto de fadas. Com relação ao enredo, destaca que, geralmente, ocorre em torno de um conflito apenas, e que os fatos se desenvolvem em uma composição clara e direta. Do mesmo modo, aparecem na apresentação dos personagens características regulares que facilitam o reconhecimento do gênero por quem lê. Ainda, determina a divisão dos personagens em protagonistas e antagonistas, também conhecidos como heróis e vilões.

Bremond (1972) utiliza os termos melhoramento e degradação para analisar a estrutura do texto narrativo. $\mathrm{O}$ autor resume o processo de melhoramento da seguinte maneira:

Coloquem-nos primeiro na perspectiva do beneficiário do melhoramento. Seu estado deficiente inicial implica a presença de um obstáculo que se opõe à realidade de um estado mais satisfatório, e que é eliminado à medida que o processo de melhoramento se desenvolve. Esta eliminação do obstáculo implica por sua vez a intervenção de fatores que agem 
como meios contra o obstáculo e a favor do beneficiário. (BREMOND, 1972, p. 117, grifo do autor)

Já a degradação é assim sintetizada por ele:

Um processo de melhoramento, chegando ao seu termo, realiza um estado de equilíbrio que pode marcar o fim da narrativa. Se escolhe prosseguir, o narrador deve recriar um estado de tensão, e, para fazer isto, introduzir forças de oposição novas, ou desenvolver germes nocivos deixados em suspenso. Um processo de degradação se instaura então. Ou pode referir à ação de fatores imotivados e inorganizados [...] neste caso, o processo de degradação permanece indeterminado ou só se especifica em má sorte, concurso de circunstâncias infelizes. Ou ao contrário, é referido à iniciativa de um agente responsável (um homem, um animal, um objeto, uma entidade antropomorfa). (BREMOND, 1972, p. 126-127)

Desta maneira, podemos visualizar o contexto da narrativa na figura a seguir:

Figura 2: Melhoramento e Degradação no texto narrativo

\begin{tabular}{|c|c|c|}
\hline \multirow{2}{*}{ Melhoramento a obter $\rightarrow$} & $\begin{array}{l}\text { Processo } \\
\text { de melhoramento } \longrightarrow\end{array}$ & $\begin{array}{l}\text { Melhoramento obtido } \\
\text { Melhoramento não obtido }\end{array}$ \\
\hline & $\begin{array}{l}\text { Ausência de processo } \\
\text { de melhoramento }\end{array}$ & \\
\hline \multirow{2}{*}{ Degradação previsível } & $\begin{array}{l}\text { Processo } \\
\text { de degradação }\end{array}$ & $\begin{array}{l}\text { Degradação produzida } \\
\text { Degradação evitada }\end{array}$ \\
\hline & $\begin{array}{l}\text { Ausência de processo } \\
\text { de degradação }\end{array}$ & \\
\hline
\end{tabular}

Fonte: BREMOND, 1972, p. 114.

As ações desenvolvidas pelo herói, pelo vilão e pelos aliados também são conceitos importantes que fazem parte da teoria de Bremond (1972). Segundo o autor, o herói é o personagem principal, ou seja, o protagonista da narrativa, que vivencia o conflito e precisa de um ou mais aliados para ajudá-lo. Neste sentido, o herói não é um príncipe ou um deus como geralmente foi construído no imaginário do leitor. O vilão é conhecido também como inimigo e os aliados, podem ser personagens humanos, objetos, espelhos mágicos, duendes, fadas madrinhas, entre outros. Estes podem atuar em favor do herói, do vilão ou até mesmo mudar de lado no decorrer da narrativa. 
Bremond (1972) esclarece que em uma narrativa sempre existe recompensa, castigo e normas transmitidas. A recompensa surge no momento em que o herói alcança o melhoramento definitivo e, em alguns casos, o aliado recebe uma recompensa, seja em bens materiais ou a própria mão do herói, neste caso, a princesa, em casamento. Já o castigo é o momento posterior, em que o inimigo é finalmente vencido, o vilão sempre recebe um castigo como a morte, a pobreza ou ainda uma humilhação pública. Por último, as normas transmitidas são mensagens de que o conto dispõe, as quais podem ser relativas, pois dependem da interação entre texto-leitor.

Assim, Coelho (2003), baseada na obra de Vladimir Propp, resume a estrutura narrativa do gênero conto e chega a seis funções comuns a todos eles:

1. uma situação de crise ou mudança: toda efabulação dos contos maravilhosos tem como motivo desencadeante uma situação de desequilíbrio da normalidade, a qual se transforma em desafio para o herói;

2. aspiração, desígnio ou obediência: o desafio é aceito pelo herói como ideal, aspiração ou desígnio para ser alcançado;

3. viagem: a condição primeira para a realização desse desígnio é sair de casa: o herói empreende uma viagem ou se desloca para um ambiente estranho, não-familiar;

4. desafio ou obstáculo: há sempre um desafio à realização pretendida, ou surgem obstáculos aparentemente insuperáveis que se opõem à ação do herói;

5. mediação: surge sempre um mediador, entre o herói e o objetivo que está difícil a ser alcançado, isto é, surge um auxiliar mágico, natural ou sobrenatural, que afasta ou neutraliza os perigos e ajuda o herói a vencer;

6. conquista: finalmente o herói vence ou conquista o objetivo almejado (via de regra, casa-se com a princesa). (COELHO, 2003, p. 113)

Se os contos de fadas tem essa estrutura em sua composição, muitas vezes os recontos, também conhecidos como contos de fadas modernos, mantêm essa ordem; alguns chegam a questionar a moralidades do conto de fadas, transgredindo a sequência narrativa estabelecida pelo autor.

\section{A categoria reconto}


Outro livro destinado às crianças bastante presente no mercado atual e, consequentemente, nas escolas de ensino básico, é o reconto. Há várias definições para esse tipo de livro. Alguns autores consideram, inclusive, as adaptações e traduções como recontos. Outros, como Aguiar (2012), o diferenciam explicando que "[...] a adaptação mantém a história original, reescrita segundo as necessidades de leitores específicos, enquanto o reconto dá-lhe roupagem diferente, mantendo, contudo, referências evidentes à fonte." Entre os autores que entendem as adaptações e traduções como parte dos recontos, está Silva (2012). Ele acredita que paráfrases, paródias, atualizações, livros modificados aligeiradamente e os remodelados de forma criativa, também fazem parte do grupo de recontos. Segundo o autor, ao modificar o texto original, o narrador ainda pode optar pelo tom com que vai narrar sua história, o qual pode ser "[...] sensível ou lírico, lúdico ou caricatural, reflexivo ou metafórico, moralista ou admonitório" (SILVA, 2012, p. 26).

O reconto tem sido bem aceito pelos pequenos leitores. Cremos que um dos motivos se deva às temáticas que, muitas vezes, aparecem atualizadas, com a presença do humor, o que facilita a recepção de leitores iniciantes. Quando um texto é bem aceito, já é grande a possibilidade de melhor compreensão. Ademais, o leitor pode conhecer a história tradicional e se sentir instigado, curioso para verificar quais novidades irá encontrar, sente-se seguro diante do que já conhece, mas, ao mesmo tempo, estimulado a ler e apreciar novos caminhos, novos enredos, novas ações de personagens, finais diferentes, entre outros. Énessas ocasiões em que se percebe o poder da literatura: o de sempre dizer e mostrar ao homem suas necessidades, seja com palavras ou com imagens.

\section{O texto verbal no livro infantil}

Em um livro infantil, o aspecto verbal é um fator de extrema importância. A linguagem literária

é um discurso carregado de vivência íntima e profunda que suscita no leitor o desejo de prolongar ou renovar as experiências que veicula. Constitui um elo privilegiado entre o homem e o mundo, pois sugere as fantasias, desencadeia emoções, ativa o nosso intelecto, trazendo e produzindo conhecimento. (BRANDÃO; MICHELETTI, 1997, p. 22) 
É essencial conhecer as especificidades da linguagem literária, da estrutura narrativa e seus elementos, como os personagens, o foco narrativo, o espaço e o tempo. Tais traços devem ser complementares entre si.

O enredo precisa propiciar relações causais que articulam a narrativa e deve estar atrelado ao contexto da história. O tempo é o momento em que a história ocorre e quanto dura. O espaço é o lugar onde acontece a narrativa. O tema corresponde à ideia tácita, que pode ser uma ou mais, como amizade, amor, coragem, entre outras. A caracterização, além das características físicas dos personagens, é a descrição de sua personalidade: como pensam, falam, agem e sentem. Finalmente, o estilo literário consiste nas palavras adotadas para compor o texto e a maneira como são organizadas, criando, consequentemente, o espírito da história. Dentre as possibilidades que podem ser encontradas, temos as frases curtas, as descritivas e os balões (FEBA; VALENTE, 2016). A combinação do texto verbal com as imagens desperta a curiosidade e a vontade de ler o livro infantil.

\section{O texto visual no livro infantil}

Tão importantes quanto o texto verbal, os textos visuais cumprem igualmente uma função muito relevante na literatura infantil. A ilustração tem finalidades e deve ser lida e descoberta pelos pequenos leitores. Assim, é grande a chance de se fazer uma leitura mais agradável, além de se atingir profundidade na compreensão da leitura.

Linden (2011, p. 121) salienta que "[...] articulados, textos e imagens constroem um discurso único. Numa relação de colaboração, o sentido não está nem na imagem nem no texto: ele emerge da relação entre os dois."

Na mesma perspectiva, Faria (2010) argumenta que "[...] nos bons livros infantis ilustrados, o texto e a imagem se articulam de tal modo que ambos concorrem para a boa compreensão da narrativa" (FARIA, 2010, p. 39) e que, para isso, devem ser empregadas de forma adequada as "[...] funções de cada linguagem: a escrita e a visual” (p. 39), isso significa que professores e alunos necessitam estar conscientes de que a leitura do verbal 
é diferente da leitura da imagem, já que esta última tem uma lógica iconográfica (FARIA, 2010).

É frequente encontrarmos nas ilustrações tanto ações escritas representadas, quanto ações não relatadas pelo texto, , ainda assim, isso é de extrema importância para a compreensão do enredo. Sobre isso, a autora realça que as ilustrações podem ser de repetição ou de complementaridade, dependendo dos propósitos do livro e da percepção do autor sobre ilustração em obras infantis. No primeiro caso, como o próprio nome diz, a imagem repete o que está escrito no texto. Esse tipo de associação é viável no trabalho com crianças bem pequenas, que estão tendo os primeiros contatos com a leitura, pois permite familiarizá-las quanto à relação texto/imagem. No segundo caso, a ilustração expressa aquilo que não está no texto verbal, ou seja, complementa-o. Isto posto, as incumbências da imagem no livro ilustrado seriam a de elaborar, propor, adicionar o espaço da página quanto à descrição e evidenciar as principais partes da narrativa pela duplicação visual (FARIA, 2010).

Diante do exposto, na escolha de um livro infantil para leitura e oferta a pequenos leitores, devemos levar em consideração o texto verbal, o texto visual, bem como os paratextos - aqueles que anunciam o conteúdo do livro e despertam a vontade de ler.

\section{Os desconhecidos paratextos}

Nos livros infantis, há ainda outro elemento que contribui para a compreensão da narrativa, contudo, quase sempre não é reconhecido, tampouco explorado pelos professores e mediadores de leitura e, consequentemente, pelos alunos. Aludimo-nos aos paratextos. Lluch (2006, p. 217) os define como "[...] elementos do livro ou de fora do livro, mas que a ele se referem, e que não são o relato." Para a autora, os paratextos têm as seguintes funções:

- Ajudar o leitor a introduzir-se na leitura, facilitando as primeiras impressões sobre o conteúdo do livro;

- Funcionar como uma porta de entrada, de transição e de transação à leitura;

- Exercer uma acção sobre o público leitor para conseguir que o texto seja bem acolhido e que a leitura deste seja mais adequada, mais pertinente aos olhos do autor e dos seus aliados; 
- Converter o texto em livro e propô-lo como tal ao público, antes que ao leitor. (LLUCH, 2006. p. 217)

Além das funções acima mencionadas, de acordo com Lluch (2006), as principais contribuições dos paratextos são que eles influenciam a recepção, e os leitores tendem a realizar hipóteses sobre a narrativa; por conseguinte, os paratextos auxiliam para a compreensão, além de favorecer a escolha adequada de um título.

Alguns exemplos de paratextos, e que serão discutidos neste artigo, são: capa, título, guardas, frontispício e quarta capa dos livros.

A capa é de extrema importância, afinal grande parte dos leitores escolhem seus livros através dela. Ao referir à capa, consideramos também a relevância da ilustração e do título; este último discutiremos adiante. Além de que, o projeto gráfico (escolha das cores, do modelo da fonte, do tamanho da fonte, da ilustração etc.) interfere na nossa compreensão. Para Nikolajeva e Scott (2011), ao produzir uma capa, pode haver distintas intenções por parte do autor ou ilustrador de um livro, entre as quais a de "[...] contradizer uma história em si”, de expor o "[...] episódio mais dramático ou atraente da história", ou, ainda, de "[...] repetir alguma passagem do interior do livro" (NIKOLAJEVA; SCOTT, 2011, p. 312-314).

Segundo Linden (2011, p. 57), a capa "[...] transmite informações que permitem apreender o tipo de discurso, o estilo de ilustração, o gênero... situando assim o leitor numa certa expectativa. Tais indicações podem tanto introduzir o leitor ao conteúdo, como levá-lo a uma pista falsa."

O primeiro contato do leitor é, para Lluch (2006, p. 219), a capa, e neste sentido, a autora enfatiza que por ser "a primeira coisa que o comprador vê, este é o paratexto que mais informação acumula: o nome do autor e ilustrador, o título, a ilustração, o nome e o anagrama da coleção e da editora."

Assim como a capa, os títulos também são pensados de variadas maneiras. A seleção depende do intuito do autor, do ilustrador ou da editora. Alguns tipos de títulos são: os nominais, em que os livros trazem o nome do personagem principal; "a 
combinação de um nome e um epíteto"”2 (NIKOLAJEVA; SCOTT, 2011, p. 309), como, por exemplo Os três porquinhos trabalhadores; ou pelo objetivo primordial da história, como A fome do Lobo; e os chamados narrativos, ou seja, que acabam por resumir o conteúdo da narração, Contos de princesas é um exemplo.

Para Lluch (2006, p. 220), o título cumpre diferentes funções:

[...] a identificação, já que a obra adquire identidade a partir do seu título, funcionando quase como o nome próprio das pessoas; a descrição, quando traz informação sobre a temática e o gênero do texto; e uma função conotativa, quando pretende seduzir o comprador.

Com isso, salientamos que, independentemente do tipo de título, ele e a ilustração devem estar associados para que possam passar as informações necessárias e contribuir para a compreensão do texto, isto é, levar o leitor a inferir, criar expectativas na leitura e sentir-se motivado a ler.

Quanto às guardas, também quase não são conhecidas pelas crianças, porque nem sempre são explicadas e trabalhadas pela maioria dos docentes, trata-se, segundo Linden (2011, p. 59), "[...] de um momento importante, o da abertura em duas acepções: de um objeto de duas dimensões passando para uma terceira, a abertura do assunto."

As guardas dividem-se em iniciais e finais. As iniciais, geralmente antecipam a história e é comum se retornar a ela nas finais. (LINDEN, 2011). Ainda, Nikolajeva e Scott (2011) expõem outras particularidades importantes das guardas, as quais devem ser reparadas pelos leitores iniciantes: na maioria dos livros ilustrados, elas são brancas ou neutras; podem semelhantemente realçar diversas vezes o personagem principal, revelando ao leitor ações que raramente aparecem na narrativa; em alguns casos, a história pode iniciar na guarda inicial e, por último, apesar de serem idênticas (inicial e final), também podem ser pensadas para realçar mudanças ocorridas durante o livro.

Infelizmente, é comum encontrarmos, nas escolas, livros que não têm guardas, em geral aqueles em que as editoras não se preocupam com a materialidade do livro, tampouco com essa espécie de paratextos. Asseguramos que, além das citadas acima, a

\footnotetext{
${ }^{2}$ Epíteto: sobrenome, apelido, adjetivo, cognome.
} 
função das guardas também é a de contribuir para complementar os sentidos de um texto.

No frontispício, mais conhecido como folha de rosto, constantemente enfatizamse as principais informações do livro, como título, autor(a), ilustrador(a), editora, local e ano de publicação. Pode também trazer uma ilustração, com o objetivo de incentivar nos leitores uma provável interpretação do enredo. Assim como pode ocorrer nas guardas e na capa, Nikolajeva e Scott (2011, p. 318) ressaltam que, “[...] às vezes, a narrativa pode começar no frontispício". Sobre isso, Linden (2011, p. 61) acrescenta que "[...] ela pode orientar a leitura ou sugerir uma interpretação." Confirma-se, assim, a relevância da apreciação desse aspecto e, por isso, deve ser ensinado para os alunos.

Por último, para a quarta capa de um livro, conhecida como contracapa, não há um modelo a ser seguido, mas tem como função, essencialmente: apresentação da síntese da narrativa; exposição do autor e ilustrador, muitas vezes seguida de foto; indicação do público para a leitura e demais títulos pertencentes à mesma coleção.

A esse respeito, destacam Nikolajeva e Scott (2011, p. 319):

Em muitos livros ilustrados, a quarta capa continua a imagem da capa, de forma que, quando abertas, constituem uma ilustração inteira. Entretanto, é raro encontrar detalhes essenciais na quarta capa complementando ou contradizendo a história. Provavelmente, isso se baseia em nossas convenções de leitura: quando terminamos de ler 0 texto verbal do livro, supomos que a história acabou e não prestamos muita atenção na quarta capa.

Diante de todos os elementos constitutivos de um livro infantil, da riqueza das discussões que podem ser planejadas pelo docente para que seus alunos se integrem à leitura e busquem descobrir as narrativas mais empolgantes dos acervos da biblioteca escolar, devemos trazer também algumas de nossas preocupações. Almejamos compartilhar nesse artigo, que,

muitas vezes, é apenas o conto simplificado que o docente tem para utilizar em seu trabalho diário, em razão de ser comum que livros de boa qualidade sejam "trancados" em armários porque a gestão das escolas receia que os alunos possam estragá-los. Assim, 
consideramos que o professor tem de ter condições de trabalhar diversos tipos de materiais e, se ele conseguir analisar minimamente uma variedade de livros, sejam eles contos de fadas, recontos ou até mesmo contos simplificados, já teria condições de selecionar suas leituras e desenvolver uma prática intencionalmente planejada com seus discentes.

Recuperando todas as discussões acerca da importância da compreensão da leitura e das características do livro infantil, mais especificamente, do conto de fadas, elegemos o conto simplificado Chapeuzinho Vermelho, da coleção Histórias Clássicas, encontrado no acervo da escola participante da pesquisa para fazer uma análise a respeito dos paratextos, do texto verbal e das imagens. O objetivo de tal análise é demonstrar aos leitores desse escrito a importância de observar as características que favorecem ou não o trabalho com o livro infantil.

No que se refere aos paratextos, pretendemos averiguar como estes contribuem e se contribuem para a compreensão da narrativa, antes mesmo de iniciar as leituras de cada livro. Já no texto visual, conversaremos sobre as ilustrações, se elas podem favorecer ou auxiliar a compreensão da obra. No texto verbal examinaremos se e como o conto segue a estrutura característica do gênero conto de fadas e como o texto foi elaborado.

\section{Apresentação do conto selecionado}

O conto simplificado Chapeuzinho Vermelho é da editora Avenida, fundada em 2004, de uma gráfica na região sul do Brasil. Além de livros infantis, serve ao mercado de lojas populares com dicionários, atlas, livros da literatura brasileira e livros gigantes para ler e pintar. O volume integra a Coleção Histórias Clássicas, a qual tem, ainda, os títulos: $A$ Bela e a Fera, Bambi, Branca de Neve, João e o pé de Feijão, Os três Porquinhos, Patinho Feio, Peter Pan, Pinóquio e Rapunzel. Não há informação no livro a respeito de quem seria o autor da história, apenas da empresa que o ilustrou, a MW Editora e llustrações. 


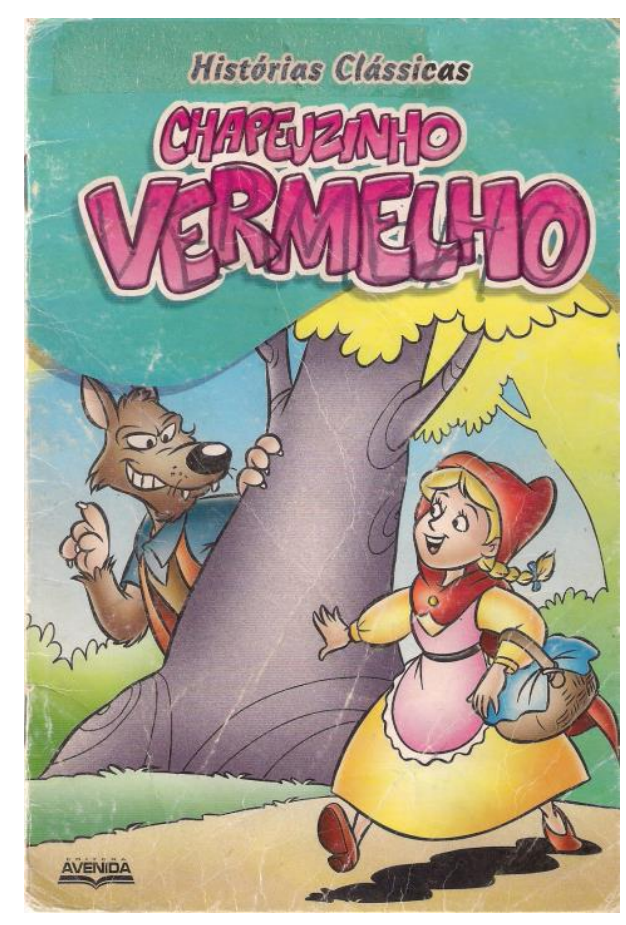

Figura 1: Chapeuzinho Vermelho Fonte: Escola.

A história começa com a apresentação de Chapeuzinho Vermelho e a explicação da procedência de seu nome. O motivo de a garota ser conhecida como Chapeuzinho Vermelho é porque sua mãe fez para ela um capuz vermelho. Na sequência, sua mãe pede para a menina levar doces para sua avó. Quando a garota atravessava o bosque, porém, encontrou com um lobo que queria devorá-la, mas não podia, pois naquele momento havia muitos caçadores por perto. O lobo decidiu, então, perguntar para onde a menina estava indo. Chapeuzinho, além de responder, explicou onde ficava a casa da avó. Logo, o lobo pegou um caminho mais curto e chegou antes da jovem. Lá, imitou a voz de Chapeuzinho para a velha senhora abrir a porta. Assim que a vovó abriu, ele entrou e a devorou. Vestiu suas roupas e ficou à espera da menina. Quando Chapeuzinho chegou, estranhou a voz rouca que a mandou entrar e, quando já estava lá dentro, desconfiou dos olhos e do nariz grandes da avó. Ao contestar o tamanho da boca, o lobo pulou sobre ela, mas a menina conseguiu escapar. Os gritos de Chapeuzinho foram ouvidos por um caçador que apareceu e tirou a vovó da barriga do lobo. A narrativa termina ao anunciar um final feliz. 


\section{Análise do conto simplificado}

O conto simplificado Chapeuzinho Vermelho é um exemplar vertical $-20 \mathrm{~cm}$ (altura) x 13,5 cm (largura) - de papelão, com capa brilhante e páginas foscas. Tem quatro folhas reunidas por dois grampos e o material adotado interfere na durabilidade, porque, conforme é manuseado, amassa e rasga com facilidade. A junção por dois grampos também favorece a soltura das páginas.

A capa apresenta o título, a coleção, a editora e uma ilustração, esta última que se repete no interior do livro. A respeito disso, Nikolajeva e Scott (2011, p. 312) asseveram que a "imagem de capa, que se repete dentro do livro, mesmo com uma leve variação, antecipa o enredo e, junto com o título explícito [...] fornece algumas informações sobre a história, o gênero e o destinatário do livro."

No conto, todavia, é notório que se trata de uma ilustração estereotipada, visto que o lobo é mostrado com expressão de esperteza e Chapeuzinho com semblante inocente e feliz. Abramovich (2001) salienta que é importante refletirmos a respeito dos estereótipos porque são "estreitadores da visão das pessoas e de sua forma de agir e de ser” (p. 40), sobretudo, auxiliar a criança leitora a notar isso nos materiais a que tem acesso para que perceba o preconceito velado nessas ilustrações. Assim como o texto verbal, estão implicados no texto visual: as relações de poder; o bonito, rico, bom e branco de um lado e, de outro, o feio, pobre, mal e negro. Livros desse padrão pouco levam seus leitores a pensar nas relações da vida porque criam certos modelos, tais como: as crianças são comportadas e bem tratadas; os avós são gordos, usam óculos, mantém-se sentados e raramente agem; ladrões ou lobos são feios, assustadores e usam roupas sujas e rasgadas e muitos outros. Assim:

Saber interpretar o momento, ampliar os referenciais, não se limitar com estereótipos, não endossar os disparates impostos, não reforçar os preconceitos, é buscar talvez no estético o momento de ruptura, de transgressão, onde não haja falsas e tolas correspondências, mas descobertas de toda a sedução encoberta, da beleza e sabedoria a serem reveladas [...] (ABRAMOVICH, 2001, p. 41) 
Embora estejamos tratando de capa, entendemos ser oportuno demonstrar algumas ilustrações no interior do livro, que coincidem, em parte, com a citação acima.

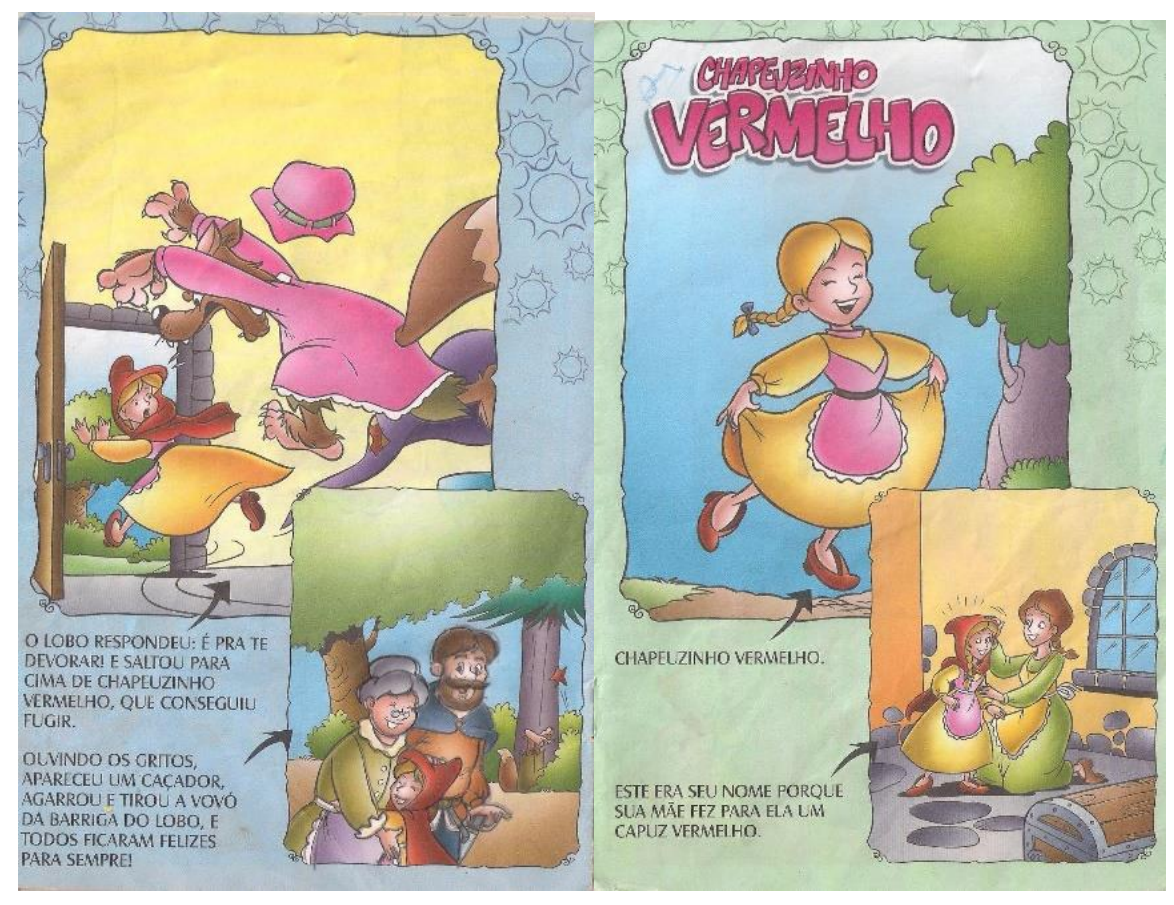

Figura 2: llustrações estereotipadas Fonte: Escola.

Na página à esquerda, verifica-se a avó de coque e óculos e, na página do lado direito, a mãe de Chapeuzinho Vermelho usa avental, confirmando que se trata de ilustrações estereotipadas.

De acordo com Linden (2011, p. 57), é na capa que ocorrem os “[...] primeiros olhares, primeiros contatos com o livro. Lugar de todas as preocupações de marketing, a capa constitui antes de mais nada, um dos espaços determinantes em que se estabelece o pacto da leitura."

Quanto ao título, é Chapeuzinho Vermelho, em outras palavras, título nominal, aquele que se refere ao protagonista da história. Não há guardas. O livro abre com a narrativa na primeira página, o que não quer dizer que a ausência desse paratexto faça com que a obra seja de baixa qualidade, embora não propicie as vantagens que os paratextos oferecem no momento da escolha do livro, o que pode colaborar para o desinteresse na leitura do material. Também não possui frontispício.

No que diz respeito à quarta capa, os editores repetem a informação sobre a coleção à qual o livro está vinculado, o título da obra, outros títulos da mesma coleção e o 
logotipo da editora, porém, a quarta capa não disponibiliza uma prévia daquilo que o leitor irá encontrar na narrativa, porque não fornece uma síntese da história nem o contextualiza.

É evidente que este conto simplificado possui desvantagens, a começar pelo material da capa e da quarta capa, o qual é constituído por papelão, tipo de papel que, mesmo sendo manuseado com cautela, pode rasgar e amassar facilmente. Com relação aos recursos da capa, os editores repetem uma imagem estereotipada, que também está dentro do livro. Enfatizam Nikolajeva e Scott (2011, p. 307):

Se a capa de um romance infantil serve como decoração e no máximo pode contribuir para o primeiro impacto geral, a de um livro ilustrado muitas vezes é parte integrante da narrativa, principalmente quando sua ilustração não repete nenhuma das imagens internas do livro.

A inexistência de guardas e frontispício pode ser prejudicial no momento da escolha do exemplar para a leitura, pois “[...] as guardas do livro podem comunicar informações essenciais e as imagens nos frontispícios podem tanto complementar quanto contradizer a narrativa" (NIKOLAJEVA; SCOTT, 2011, p. 317). Em acréscimo, no que se refere à quarta capa, Lluch (2006, p. 219) afirma: “A contracapa está reservada para o resumo do argumento e nos livros para os mais pequenos é incluída uma informação dirigida aos adultos sobre as características do livro." Nikolajeva e Scott (2011, p. 320) acrescentam que as quartas capas

[...] são frequentemente usadas para paratextos como um breve resumo do enredo, uma apresentação do autor e ilustrador (às vezes com uma foto), uma recomendação sobre a idade do leitor, trechos de resenhas, informações sobre outros livros dos mesmos autores e coisas parecidas.

No caso em apreço, não se trata de expor outros livros do mesmo autor, visto que não há a presença de um responsável pelo material, mas marcar o interesse de vender os outros títulos que compõem a mesma coleção. 
Claro está, portanto, que, primeiramente, é preciso que os educadores saibam as funções, as contribuições e a relevância de ler e saber explorar os paratextos e outras informações que antecedem e finalizam a leitura, para, em seguida, fazer uso desses ensinamentos nas aulas com seus alunos, uma vez que comprovamos que os paratextos não estão presentes nos livros para embelezá-los, mas sim têm propósitos e podem colaborar e até ser indispensáveis para a compreensão da história.

Temos constantemente citado e discutido que os livros infantis têm, em sua maioria, além do texto verbal, o visual, ou seja, a ilustração. As ilustrações não estão postas apenas para servir como ornamento nas histórias: elas têm diferentes funções e existem para colaborar na compreensão da narrativa. Dessa forma, é necessário que os professores, antes de lerem ou indicarem leituras para seus alunos, saibam analisar tais funções e ensinem seus alunos a perceberem o papel das imagens, em cada livro, bem como a articulação entre texto verbal e visual.

Para Camargo (2014, p. 1), “[...] ilustração é uma imagem que acompanha um texto." Ele acrescenta:

\footnotetext{
Como toda imagem, a ilustração pode representar, descrever, narrar, simbolizar, expressar, chamar atenção para sua configuração visual ou seu suporte, para a linguagem visual, incentivar o jogo, procurar interferir no comportamento, nos valores e nas atitudes do observador, além de pontuar o texto que acompanha, isto é, destacar seu início e seu fim, ou chamar atenção para elementos do texto. (CAMARGO, 2014, p. 1)
}

Nesta versão simplificada, as ilustrações aparecem dentro de quadros sobrepostos e emoldurados, dois a cada página, o que limita a leitura. Essa característica pode restringir o poder de criação e de imaginação do leitor e, no caso em estudo, as molduras cumprem a função exclusivamente de adereço. Quanto aos quadros, ousamos sustentar que existem apenas como forma de economizar páginas. Além disso, cabe relembrar o que já discutimos anteriormente, de as ilustrações desse livro serem de figuras estereotipadas em que a menina, no caso Chapeuzinho, tem semblante inocente; a mãe aparece usando um avental, por isso, entende-se ser dona de casa; a vovó usa coque e óculos caídos sobre o nariz; quanto ao lobo, quando não aparece com expressão de mau, mostra-se com olhar de esperteza. 
Trata-se, por fim, de ilustrações que apenas representam o texto verbal e não deixam margem para a criação do leitor. Esse é um tipo de imagem válida, a qual tem como objetivo fazer com que a criança relacione-a com o texto escrito, todavia, nessa versão, a maneira como a ilustração está posta não permite tal relação. Há ainda o fato de existirem setas, em todo o livro, que saem do texto verbal em direção à ilustração à qual ele se refere. Dessa forma, não favorece que os leitores façam a relação entre texto/imagem. Além disso, tudo - texto e ilustração - está pronto e não há a possibilidade de criar, imaginar e fazer relações entre esses textos.

Sobre o texto verbal, consideramos essencial, para o leitor, compreender alguns aspectos da estrutura do gênero: elementos maravilhosos, situação inicial/desenvolvimento/desfecho, espaço, tempo, enredo, caraterísticas dos personagens, recompensa/castigo/normas transmitidas.

A presença de elementos maravilhosos encontra-se no livro em análise, dado que o lobo é personificado e fala. Percebe-se, com isso, a fantasia presente.

A personificação corresponde aos procedimentos de atribuição de características humanas a seres de outros reinos, bem como a idéias abstratas [...] e extremamente comum na produção visual dirigida à criança, como o desenho animado, histórias em quadrinhos, ilustração etc., tanto assim que a personificação pode ser considerada um traço característico do gênero. (CAMARGO, 1998, p. 68, grifo do autor)

Quanto à estrutura do texto verbal, há que se iniciar a análise verificando a introdução, o começo da narrativa. No conto simplificado, não há essa apresentação inicial, pois as primeiras palavras são "Chapeuzinho Vermelho"3 (e se aponta uma seta para a ilustração do personagem). Abaixo: “Este era seu nome porque sua mãe fez para ela um capuz vermelho" (s/n). Entende-se que a primeira frase é a repetição do título, desnecessária e sem nenhuma introdução prévia, além de não mencionar o espaço onde se passa a narrativa.

\footnotetext{
${ }^{3}$ Nas reproduções das passagens do conto simplificado, infelizmente, não poderemos fazer a citação de acordo com as normas, pois o livro não traz as informações necessárias: autor, ano de publicação e numeração de páginas.
} 
Percebe-se que o desenvolvimento no conto simplificado é o momento em que a mãe pede para Chapeuzinho levar doces para a avó, depois, quando encontra o lobo e pela chegada deste na casa da vovó. A qualidade do escrito é baixa, pois as frases são curtas e muitas vezes sintetizam as ações dos personagens, sem contribuir para a compreensão do todo.

Sobre o clímax, Gancho (2002, p. 11) afirma que "[...] é o momento culminante da história, isto quer dizer que é o momento de maior tensão, no qual o conflito chega a seu ponto máximo. O clímax é o ponto de referência para as outras partes do enredo, que existem em função dele."

Nessa versão, o clímax acontece diante da suposta morte da avó, a qual chega a ser engolida, mas é salva posteriormente pelo caçador que ouviu os gritos da menina e salvou a vovó: "Imitou a voz de Chapeuzinho Vermelho para a avó abrir a porta. O lobo entrou, avançou e devorou a vovó" (s/n).

No desfecho, Chapeuzinho Vermelho consegue fugir e um caçador tira a vovó viva da barriga do animal.

Quanto ao espaço, a narrativa se passa no bosque e na casa da avó, contudo, sem descrição desses locais. Quando aludimos ao tempo, estamos nos referindo à época em que as ações acontecem. Nos contos de fadas, isso significa ser possível identificar que todos eles estão escritos no pretérito, porém, não é possível discernir o momento dos acontecimentos. Importante salientar a escolha das palavras que compõem o texto do conto da versão simplificada.

Falamos da escolha das palavras, para alertarmos ao fato de, nessa versão, o texto não conter elementos de ligação, conectivos: são frases soltas, fragmentadas. Assim, as ações da narrativa não fazem tanto sentido porque essa condição não possibilita que haja clímax ou o faz ser mal construído. Como exemplo da falta de conectivos, podemos verificar a passagem em que a mãe de Chapeuzinho pede para a menina levar doces para a avó: "Sua mãe pediu para Chapeuzinho Vermelho levar doces para a avó" (s/n). "Quando atravessava o bosque, a menina encontrou um lobo". (s/n) "O lobo queria devorar a menina mas ali não podia. Estava cheio de caçadores por perto". (s/n) "O lobo perguntou: - ‘Aonde a menina está indo?’”(s/n). Fica explícito que essas frases poderiam 
ser ligadas com os conectivos mas, que, porém, pois; assim, seria resolvido o problema da repetição das palavras lobo e menina. Refeita, uma das possibilidades dessa passagem teríamos: "Sua mãe pediu para Chapeuzinho Vermelho levar doces para a avó, mas, quando atravessava o bosque a menina encontrou um lobo que queria devorá-la, porém, ali não podia, pois estava cheio de caçadores por perto. O lobo perguntou: - Aonde está indo?".

Frisamos, ainda, que em todo o conto simplificado há apenas dois momentos de fala dos personagens: o primeiro, quando o lobo pergunta: “Aonde a menina está indo?" (s/n) e o segundo, quando Chapeuzinho exclama: "Que olhos grandes!” (s/n), "Que nariz grande" (s/n), "Que boca grande" (s/n), seguidamente, sem a presença da resposta do lobo. O restante do texto verbal é apenas narrado, o que também colabora para que o clímax na narrativa seja diluído, além de demonstrar autoridade do narrador, isto é, um tipo de texto que não chama a participação do leitor.

O texto que finaliza a história é: "O lobo respondeu: é pra te devorar! [sem travessão] e saltou para cima de Chapeuzinho Vermelho, que conseguiu fugir". (s/n) "Ouvindo os gritos, apareceu um caçador, agarrou e tirou a vovó da barriga do lobo, e todos ficaram felizes para sempre!" (s/n) Questionamos: agarrou quem? Chapeuzinho, que estava fugindo? O lobo? Nesse ponto, nem mesmo a ilustração consegue tirar tal dúvida, pois a imagem mostra apenas a avó, a Chapeuzinho e o caçador abraçados, depois, o texto escrito traz o "Felizes para sempre!" (s/n).

Há um equívoco no que diz respeito ao tempo verbal. Em todo o livro, o relato se passa no passado, portanto, os verbos também se encontram no pretérito, tais como: “este era seu nome” (s/n), “porque sua mãe fez para ela” (s/n), "sua mãe pediu” (s/n), "quando atravessava o bosque" (s/n), e assim por diante. Todavia, no momento em que a menina chega à casa da vovó, o texto aparece da seguinte forma: "Chapeuzinho Vermelho chega, batendo à porta" (s/n); quando o correto seria: “Chapeuzinho Vermelho chegou, batendo à porta", seguindo o padrão dos verbos no pretérito exposto durante todo o livro.

Sobre o princípio de boa conduta que implicitamente pode conter o conto de fadas, neste, além de não conseguir devorar Chapeuzinho Vermelho, porque ela foge, também há a vovó retirada viva de sua barriga. Se o Lobo sobreviveu ou morreu, nem 
texto, nem ilustração respondem a essa questão. Com relação à norma transmitida, é a mesma do conto tradicional: o perigo de falar com pessoas estranhas.

Como último apontamento acerca do modo como o texto verbal é evidenciado, gostaríamos de ressaltar que a linguagem presente no livro contém uma forma direta de expressão, aligeirada, com ausência de metáforas, o que acaba por interferir negativamente na compreensão e na leitura, também porque exige pouca participação do leitor. A afirmação reforça a falta dos principais elementos que dariam ao texto aspectos de literariedade, distanciando o conto simplificado de ser um texto literário.

\section{Em tom de proposta}

É comum a presença em sala de aula e em bibliotecas escolares de versões simplificadas e nada verticais de conto de fadas. Tais textos são objeto de escolha e de leitura de alunos e professores; dos primeiros porque ainda necessitam de mediação para auxiliar na seleção de obras e autores para ler para que, com o tempo, a leitura passe a ser fruto de uma experiência pessoal. Os docentes, por sua vez, escolhem esse tipo de material de baixa qualidade porque lhes falta formação específica na área da literatura e da leitura, quesito que certamente contribuiria para a realização de uma triagem diante do mercado editorial e de boas práticas com o uso do texto literário em sala de aula.

Analisamos uma narrativa de Chapeuzinho Vermelho do ponto de vista do texto verbal, do visual e dos paratextos, bem como destacamos o que torna esta versão, escolhida pelos alunos participantes da pesquisa, um tanto distante das especificidades do texto literário e de um projeto gráfico editorial de qualidade. O nosso desejo é de ampliar o debate a respeito da eleição de obras voltadas ao público mirim e da importância de compreender que nem todos os livros destinados às crianças são considerados literatura infantil, embora muitas vezes a roupagem da obra engane o leitor.

Na tentativa de reverter esse quadro, seria importante que houvesse na escola um espaço e um momento próprios para ler, porque a narração de histórias permite o acesso do leitor a um tipo especial de linguagem e a um mundo possível de ver na realidade que o cerca, porque: 
A comunicação literária se produz desde o início e o que progride é a capacidade de construir um sentido através dos caminhos assinalados. Isto sustenta a idéia educativa de que a formação leitora deve se dirigir desde o começo ao diálogo entre o indivíduo e a cultura, ao uso da literatura para comparar-se a si mesmo com esse horizonte de vozes [...] O trabalho escolar sobre as obras deve orientar-se, pois, para a descoberta do seu sentido global, a estrutura simbólica onde o leitor pode projetar-se. A literatura oferece então a ocasião de exercitar-se nessa experiência e aumenta a capacidade de entender o mundo. Tal recompensa é o que justifica o esforço de ler. (COLOMER, 2007, p. 62)

Uma experiência com a estética da palavra poderia envolver a leitura de diferentes versões da tão conhecida e apreciada obra Chapeuzinho Vermelho. O trabalho poderia começar com um levantamento de conhecimentos prévios dos alunos, para que o docente os indagasse oralmente acerca do que sabem sobre a história e sobre outros contos de fada. Isso os ajudaria a pensar no gênero textual e em suas principais características, de modo a antecipar o que podem acessar ao ler outros textos da mesma natureza. Na sequência, os alunos poderiam ser convidados a contar a história oralmente, a fim de relembrarem o enredo e, quanto ao professor, ficaria sabendo quais as versões fazem parte do repertório de seus estudantes. Depois desta atividade oral, seria interessante ler uma versão tradicional do conto - como a de Perrault em que tanto a protagonista quanto a avó morrem, ou ainda a dos irmãos Grimm, conto em que o caçador/lenhador aparece e tira a avó e a menina da barriga do Lobo. Para tanto, os alunos estariam com cópias dessas versões nas mãos e fariam uma leitura silenciosa para, em seguida, realizarem um debate que envolveria questões, do tipo: como é narrada esta história? Em que medida é semelhante ou diferente daquelas que vocês apresentaram no início da aula?

Além disso, é sempre importante que o professor apresente o livro e leve os alunos a analisarem as ilustrações e os paratextos, assim como expomos inicialmente. Se o exemplar tiver ilustrações coloridas e se não for possível fazer cópia para os alunos, o livro poderia ser projetado para que não houvesse prejuízo na leitura.

As aulas subsequentes poderiam integrar diferentes versões e permitir a intertextualidade, o que ampliaria as possibilidades de leitura e os horizontes culturais dos alunos, contribuiria para o desenvolvimento da criatividade, permitiria a comparação 
com o primeiro texto e estabeleceria um diálogo com as questões de seu tempo. Para tal, seriam produtivas as leituras de:

a) História em quadrinhos de Maurício de Souza "Mônica em: Chapeuzinho Vermelho", na qual o lobo fica com medo da Mônica e a Magali come as guloseimas da cesta no final;

b) A verdadeira história de Chapeuzinho Vermelho, de Agnese Baruzzi e Sandro Natalini (Brinque-Book, 2013), narrativa em que o lobo quer ser bonzinho e o projeto gráfico é bem elaborado e desafia o leitor, ao trazer cartinhas e envelopes colados às páginas;

c) Fita verde no cabelo - nova velha estória, de Guimarães Rosa, em que neologismos e seleção lexical dão profundidade ao texto, que é inovador, pois traz um final, com a morte da avó e a inocência da menina;

d) Uma Chapeuzinho Vermelho, de Marjolaine Leray (Companhia das Letrinhas, 2012), na qual a letra cursiva registrada nas páginas e as ilustrações que se assemelham a rabiscos revelam um ar infantil e um olhar próprio da criança. Nesta versão surpreendente, ocorre inversão de papéis e apresenta uma menina muito corajosa;

e) Deu a louca na Chapeuzinho, um filme de animação que apresenta quatro pontos de vista diferentes acerca do sumiço do caderno de receitas da avó da protagonista;

f) “Chapeuzinho Vermelho de raiva”, de Mário Prata ([1997]), cuja vovó tem cabelo moderno e não gosta das clássicas perguntas feitas a ela a respeito de sua orelha e sua boca;

g) Era uma vez... Chapeuzinho Vermelho, da Ciranda Cultural, um livro brinquedo pertencente à coleção Carrossel de Histórias, que é acompanhado de uma caixa que funciona como um cenário. Na caixa há um mecanismo para o leitor girar e ver, por meio de uma lente, as cenas da narrativa em três dimensões.

Enfim, há muitas outras versões impressas no mercado editorial, feitas em diferentes suportes, bem como animações que podem ser lidas e/ou assistidas pelas crianças. Durante as aulas, o professor pode incitar o debate para difundir as experiências 
de leitura, compartilhar sensações e produzir significados conjuntamente, além de motivar a turma a produzir recontos, dos mais variados, com auxílio de tecnologias diversas e a partir de perspectivas temáticas que sejam condizentes com os interesses dos alunos.

Desse modo, a roupa do livro não enganará futuras escolhas, porque, quando bem articuladas com a análise dos livros infantis e com os objetivos de leitura, poderão contribuir para a formação de um leitor literário.

\section{Referências}

ABRAMOVICH, Fanny. Literatura infantil: gostosuras e bobices. 5. ed. São Paulo: Scipione, 2001.

AGUIAR, Vera Teixeira de. Do conto ao reconto: uma viagem ao presente. In: AGUIAR, Vera Teixeira de; MARTHA, Alice Aurea Penteado (Orgs.). Conto e reconto: das fontes à invenção. São Paulo: Cultura Acadêmica, 2012. p. 48-56.

BARUZZI, Agnese; NATALINI, Sandro. A verdadeira história de Chapeuzinho Vermelho. São Paulo: Brinque-Book, 2013.

BETTELHEIM, Bruno. A psicanálise dos contos de fadas. Rio de Janeiro: Paz e Terra, 1980.

BONAVENTURE, Jette. O que conta um conto? São Paulo: Paulinas, 1992.

BRANDÃO, Helena; MICHELETTI, Guaraciara. Teoria e prática da leitura. In: BRANDÃO, Helena; MICHELETTI, Guaraciara. (Coords). Aprender e ensinar com textos didáticos e paradidáticos. (Aprender e ensinar com textos, v. 2). p. 17-30. 
BREMOND, Claude. A lógica dos possíveis narrativos. In: BARTHES, Roland et al. Análise Estrutural da narrativa: pesquisas semiológicas. 2. ed. Introdução à edição brasileira e revisão de Milton José Pinto. Tradução de Maria Zélia Barbosa Pinto. Petrópolis (RJ): Vozes, 1972. p. 110-135. (Col. Novas Perspectivas de Comunicação).CAMARGO, Luís Hellmeister de. Poesia infantil e ilustração: estudo sobre Ou insto ou aquilo de Cecília Meireles. Dissertação (Mestrado em Letras na área da Teoria Literária). Instituto de Estudos da Linguagem. Campinas, 1998.

CAMARGO, Luís Hellmeister de. Ilustração em livros de literatura infantis. Glossário Ceale, Minas Gerais. [2014]. Disponível em:

<http://ceale.fae.ufmg.br/app/webroot/glossarioceale/verbetes/ilustracao-em-livros-deliteratura-infantil>. Acesso em: 05 abr. 2016.

CHAPEUZINHO VERMELHO. Local: Editora Avenida. [19--]. (Histórias Clássicas).

COELHO, Nelly Novaes. O conto de fadas. 2. ed. São Paulo: Ática, 1991.

COELHO, Nelly Novaes. $O$ conto de fadas: símbolos mitos arquétipos. São Paulo: DCL, 2003.

COLOMER, Teresa. Andar entre livros: a leitura literária na escola. Tradução Laura Sandroni. São Paulo: Global, 2007.

EDWARDS, Cory; EDWARDS, Todd; LEECH, Tony. Deu a louca na Chapeuzinho. Estados Unidos: Editora, 2005.

ERA uma vez... Chapeuzinho Vermelho. São Paulo: Ciranda Cultural, [19--]. Coleção Carrossel de Histórias.

FARIA, Maria Alice. Como usar literatura infantil na sala de aula. 5.ed. São Paulo: Contexto, 2010.

FEBA, Berta Lúcia Tagliari; VALENTE, Thiago Alves. O acervo PNBE: por dentro e por fora dos livros. In: GIROTTO, Cyntia Graziella G. Simões; SOUZA, Renata Junqueira de (Orgs.). Literatura e educação infantil: livros, imagens e práticas de leitura. Campinas: Mercado de Letras, 2016. p. 131-148.

GANCHO, Cândida Vilares. Como analisar narrativas. São Paulo: Ática, 2002.

GIROTTO, Cyntia Graziela Guizelim Simões; SOUZA, Renata. Junqueira de. In: PNBE na escola: literatura fora da caixa. [Brasília: Ministério da Educação, Secretaria de Educação Básica, 2014]. 3 v. p. 31- 44.

LERAY, Marjolaine. Uma Chapeuzinho Vermelho. Tradução Júlia Moritz Schwarcz. São Paulo: Companhia das Letrinhas, 2012.

LINDEN, Sophie Van der. Para ler o livro ilustrado. São Paulo: Cosac Naify, 2011. 
LLUCH, Gemma. Para uma seleção adequada do livro. In: AZEVEDO, Fernando (Coord.). et al. Língua materna e literatura infantil: elementos nucleares para professores do ensino básico. Lisboa: Lidel, 2006. p. 215-231.NIKOLAJEVA, Maria; SCOTT, Carole. Paratextos dos livros ilustrados. In: NIKOLAJEVA, Maria; SCOTT, Carole. Livro ilustrado: palavras e imagens. São Paulo: Cosac Naify, 2011.

PRATA, Mario. “Chapeuzinho Vermelho de raiva”. [Editora Globo, 1977]. Disponível: In: <https://marioprata.net/literatura-2/literatura-infantil/chapeuzinho-vermelho-de-raiva/>. Acesso em 25-02-2017.

RIBEIRO, Maria Augusta Hermengarda Wurthmann. Os recontos dos contos da oralidade: permanências e mudanças no gênero. In: AGUIAR, Vera Teixeira de; MARTHA, Alice Áurea Penteado (Orgs.). Conto e reconto: das fontes à invenção. São Paulo: Cultura Acadêmica, 2012. p. 215-227.

ROSA, João Guimarães. Fita verde no cabelo: nova velha estória. Ilustrações Roger Mello. São Paulo: Nova Fronteira, 1992.

SILVA, Vera Maria Tietzmann. Literatura infantil brasileira: um guia para professores e promotores de leitura. 2. ed. Goiânia: Cânone Editorial, 2009.

SILVA, Vera Maria Tietzmann. Sobre os contos e recontos. In: AGUIAR, Vera Teixeira de; MARTHA, Alice Áurea Penteado (Org.). Conto e reconto: das fontes à invenção. São Paulo: Cultura Acadêmica, 2012. p. 13-33.

Universidade do Estado de Santa Catarina - UDESC Programa de Pós-Graduação em Educação - PPGE 